\title{
Analysis of Heat and Flow Characteristics on Spray Cooling Heat Transfer with an Optimized Hexagonal Finned Heat Sink
}

\author{
Faruk Yesildal ${ }^{* 1}$ and Kenan Yakut ${ }^{2}$ \\ ${ }^{1}$ Mechanical Engineering Department, Agri Ibrahim Cecen University, Agri, Turkey \\ ${ }^{2}$ Mechanical Engineering Department, Atatürk University, Erzurum, Turkey \\ ${ }^{*}$ Corresponding author: fayesildal@agri.edu.tr
}

\begin{abstract}
An experimental study was carried out with a hexagonal finned heat sink to obtain valuable information about the thermal and flow characteristics on spray cooling. Water was used as the refrigerant fluid and was atomized by an air-assisted atomizer and some of the variables that affect spray cooling process, such as breakup length and Sauter Mean Diameter (SMD) were obtained using appropriate correlations. The parameters most influential on the Nusselt number were determined and analyzed. Experiments were conducted for optimized conditions. The jet diameter and spray angle were determined via image processing using macroscopic aspects. Nusselt were demonstrated of hexagonal finned heat sink which optimized according to the Taguchi optimization method. The results of the spray analysis showed that SMD decreases with an increase in either air-liquid mass ratio (ALR) or operating pressure resulting in a more uniform spray. As the liquid flow rate increases in all ALR values, the heat transfer rate also increases markedly. As a results of the experiments, Nusselt number, jet width and spray angle correlations were developed. The relationship of ALR-Nu was demonstrated according to fin height and spraying time.
\end{abstract}

Keywords:

Spray cooling, Spray parameters, Taguchi, Non-boiling regime

\section{Introduction}

Spray can be used for large amounts of energy transfer in low temperatures during cooling, and heat can be removed from the surface more easily than pool boiling. Thus, the heat transfer rate is higher, and the drops can be affected by mass, energy, and momentum interchanges between them. Air-assisted spray cooling is utilized more often in the industry, compared to forced air jets and pressured nozzles. Air-assist spray is currently used during some applications in which rapid cooling is required, such as cooling of plates that have a normal thickness, cooling of hot-rolled steel, tempering glass in the automotive industry, and cooling of electronic chips. Additionally, air-assisted nozzles are widely used in the food processing industry. Spray cooling is also used in advanced technology applications, such as thermal control of space stations, safety of nuclear reactors, and cooling of turbine blades [1]. The studies related to spray flow, heat transfer, and image processing in the literature are summarized below.

Researchers in [2] investigated the effects of spray on a square heated test surface was investigated to ascertain the cooling characteristics of PF-5052. Full-cone spray nozzles were used in the experiments to compare FC-72, FC-87, and PF-5052 liquids in terms of spray orientation and cooling performance. Sauter Mean Diameter (SMD) and its cooling effects also investigated. The obtained database was used to develop a general correlation between single-phase heat transfer, nucleate boiling, and CHF. The authors offered a single correlation related to nucleate boiling data for different fluids based on density ratio, We and Ja number. They also showed that the orientation was not a measurable effect on spray cooling regimes.

Researchers [3] compared continuous and intermittent spray cooling for low temperature fluxes in a single-phase regime and for high temperatures in a two-phase regime. They obtained the required cooling rate on a target surface by controlling flow rate and frequency. The efficiency of intermittent spray was higher than continuous spray, and it was also found that intermittent spray increased spray efficiency in low flow rates. Additionally, the spray angle was obtained using image processing.

Liu et al. [4] investigated the heat transfer performance on augmented surfaces during cooling by water-spraying in non-boiling regime. Surface augmentation was carried out by straight fins. The surfaces were placed on copper blocks with cross sectional areas of $0.01 \mathrm{~m} \times 0.01 \mathrm{~m}$. They showed that the heat transfer was enhanced on straight fin surfaces much more than on flat surfaces. However, they also investigated that increasing rate decreases as fin height increases.

A comprehensive review of flow-visualization techniques for analysing spray characteristics was conducted and experiments of different lighting techniques performed. Researchers [5] introduced the spray photos of airblast and swirl atomizers by using rear, slit, incident and scattered light methods. The authors showed that the photos taken 
using these methods are useful for jet breakup, internal details, and external appearances of spray. They also reached and the conclusion that combining different techniques may be necessary for achieving suitable specifications.

Charalampous et al. [6] used three techniques to measure the breakup length in airblast atomizers. First, a single high-resolution photo was taken using a high-speed shadowgraphy method to determine the breakup length and duration. Second, using an electrical conductivity method, conductivity was vertically measured in the jet. Third, the optical connectivity method was used to take photos by lighting the jet with a laser. The authors compared the advantages and constraints of these three methods.

Karwa et al. [7] cooled a copper surface with a diameter of $0.02 \mathrm{~m}$ using water spray from a pressured atomizer in the non-boiling regime. The surface was isolated and heated using electricity. The experiments were conducted in the following conditions: $35-85 \mathrm{~W} / \mathrm{cm}^{2}$ heat flux, $95^{\circ} \mathrm{C}$ surface temperature, and $2.6-9.9 \mathrm{~kg} / \mathrm{m}^{2}$ mass flow. The heat transfer coefficient was calculated between the ranges of 9,000-24,000 W/m² $\mathrm{K}$, and heat transfer increased with the increase of mass flow. The authors developed an empirical correlation related to average Nusselt and Reynolds numbers. The correlation was found to be $N u=20.344(R e)^{0.659}$. The distribution of target surface temperature was calculated by extrapolation in accordance with the method given by [2]. The results showed that the heat transfer coefficient was dramatically larger than the forced convection under non-boiling conditions.

In [8], heat transfer was investigated using deionized water in a non-boiling spray cooling system. The experiments were conducted using two full cone spray nozzles in an open-loop test system. The effects of liquid volumetric flow rate, distance between nozzle to surface and liquid inlet temperature were also investigated. The authors observed that the heat transfer coefficient increased dramatically with the increase of volumetric flow rate and decrease of liquid inlet temperature. They also pointed out that adding a surfactant to the liquid increased the heat transfer.

There are various studies in the literature on spray cooling, image processing, droplet size distribution, atomization performance [9], drop morphology [10], characterization of spray [11], injection parameters [12], and drop impact [13].

In this study, the optimum spray parameters in hexagonal finned heat sinks in the conditions of constant surface temperature and a non-boiling regime are determined using Taguchi experimental design method. In the first step, the parameters that have impacts on heat transfer, such as the distance between nozzle to surface, fin height, fin width, distance between the fins in directions $x$ and $y$, liquid and air flow rates and spraying time, were determined. The temperature of the surface was lower than the boiling temperature of the refrigerant in the non-boiling regime. The droplets accumulated on the heated surface as a moving liquid film during spraying. The heat transfer mechanism in the non-boiling regime was composed of forced convection and liquid film vaporization. As the surface temperature increased to the point of boiling in the cooler, phase transition gives the expected increase in heat flux. Spray cooling provides a controlled cooling process particularly during electronic cooling in a non-boiling regime. Spray cooling is the most effective method for metal cooling due to increasing contact between droplets and the surface. Air-assisted spray also provides advantages to this process [14].

Biot number $(\mathrm{Bi})$ should always be enumerated at the outset to identify transient conduction problems which may be treated simply as lumped parameter problems, for which $\mathrm{Bi}<0.1$ and for which it is seldom necessary to solve the conduction equation. Convection is the dominant controlling process [15]. If $\mathrm{Bi}<0.1$ it is generally accepted that lumped system analysis [16]. In this study, the Biot number was calculated to be very low for hexagonal finned aluminium heat sinks with constant surface temperature in a non-boiling regime; thus, the total mass approach was used. In this case, convection was the dominant heat transfer mechanism and rate-controlling process. The heat removed from the aluminium surface was calculated as;

$$
Q=m_{A l} C_{p} \Delta T
$$

$\Delta T$ is the difference of average surface temperatures before and after spraying. The heat transfer coefficient is defined below as a spray heat transfer coefficient $\left(h_{s p}\right)$;

$$
h_{s p}=\frac{\left(Q-Q_{r a d}-Q_{e v p}\right)}{A_{y}\left(T_{s}-T_{s p}\right)},
$$

where the Nu number defined as

$$
N u=\frac{h_{s p} D}{k}
$$

The effect of heat transfer by radiation was calculated according to the average temperature of the surface during spraying. The heat removed by evaporation was calculated for different spraying times based on the change in relative humidity on the surface. The humidity was measured before and after spraying. Measurements were taken over the finned surface $(1 \mathrm{~cm})$ with different stations by humidistat. The average evaporation rates are obtained as $16 \%, 17 \%$ and $22 \%$ for spraying time of 5 s, 10 s, and 15 s, respectively.

\section{Material and methods}

Spray cooling is an effective heat convection method and is widely used in engineering applications. Most experimental data and explicative models have been developed over years for all stages. These stages are drop forming, diameter-velocity distribution, drop-air interaction, impact and dispersion mechanisms, and drop-surface 
heat transfer. Surface tension, outlet velocity of liquid drop, and flow rate affect the liquid breakup mechanisms. Spray drops are characterized by diameter, velocity, and three-dimensional distributions.

In the hexagonal finned heat sinks, the advantages of air-assisted spray cooling over air jet and pressured water spray cooling were investigated in terms of optimized geometrical and operational spray parameters. Using an experimental system (Figure 1), the outlet velocity of spray from the nozzle, droplet diameter, SMD, and jet diameter parameters were determined by image processing and relevant correlations. The images were processed using Matlab GUI to investigate the spray flow parameters. SMD values were calculated using the correlations offered by Shanawany [17] (Eq. 4) and Feras [18] (Eq. 5).

$$
\frac{\mathrm{D}_{32}}{\mathrm{D}_{\mathrm{h}}}=\left(1+\frac{\dot{\mathrm{m}}_{\mathrm{L}}}{\dot{\mathrm{m}}_{\mathrm{A}}}\right)\left[0.33\left(\frac{\sigma}{\rho_{\mathrm{A}} \mathrm{U}_{\mathrm{A}} \mathrm{D}_{\mathrm{p}}}\right)^{0.6}\left(\frac{\rho_{\mathrm{A}}}{\rho_{\mathrm{L}}}\right)^{0.1}+0.068\left(\frac{\mu_{\mathrm{L}}^{2}}{\sigma \rho_{\mathrm{L}} \mathrm{D}_{\mathrm{p}}}\right)^{0.5}\right]
$$

In this dimensionless correlation, the hydraulic diameter $\left(D_{h}\right)$ was calculated as $D_{h}=2 d_{0}$. $D_{p}$ is the characteristic diameter for the atomizer [19].

$$
D_{32}=0.95 \frac{\left(\sigma \mu_{L}\right)^{0.33}}{\rho_{L}^{0.37} \rho_{A}^{0.3} U_{A}}\left[1+\frac{\dot{m}_{L}}{\dot{m}_{A}}\right]^{1.7}+0.13\left(\frac{\mu_{L}^{2} d_{0}}{\sigma \rho_{L}}\right)^{0.5}\left(1+\frac{\dot{m}_{L}}{\dot{m}_{A}}\right)^{1.7}
$$

The instruments used for measurements were installed in accordance with the system guidelines. Surface heat dissipation was measured and processed using a TESTO 875-2 thermal camera. The thermal camera in steadystate conditions was used to evaluate the average surface temperature before and immediately after spraying. The changes in Nusselt-ALR were investigated for different spraying times (Fig. 5) and fin heights (Fig. 6). For the heat sink to be heated at a constant temperature, water/oil bath with a circulator was established and the reactor was designed and manufactured. The top of the reactor was heated by the water/oil bath according to the heat sink's dimensions. The base plates were made of aluminum and were $0.3 \mathrm{~m}$ long, $0.3 \mathrm{~m}$ wide, and $0.008 \mathrm{~mm}$ height. It was surrounded by heat insulation.

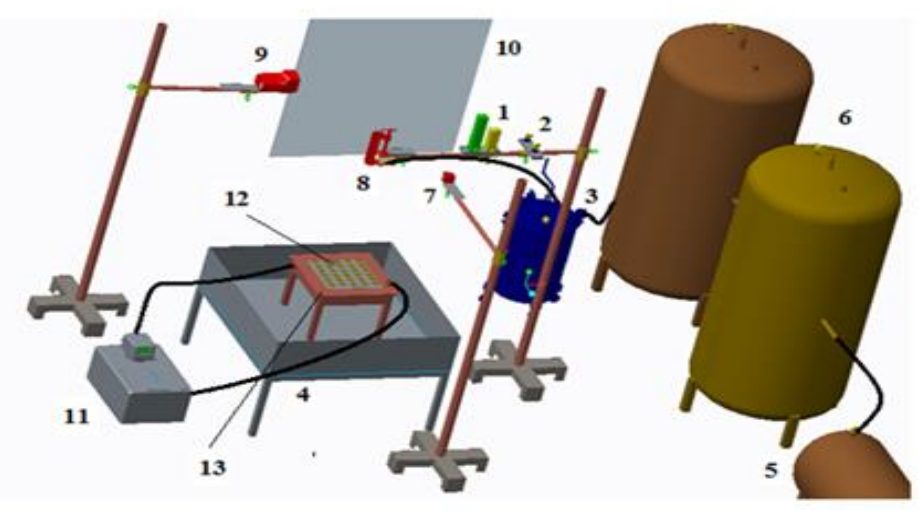

Figure 1. Experimental apparatus (1-Flowmeters, 2-Manometers, 3-Pressurized water tank, 4-Reservoir, 5-Compressor, 6-Air tank, 7- CCD camera, 8-Nozzle, 9-Stroboscope, 10-Black background, 11-Water/oil Bath, 12-Hexagonal finned heat sinks, 13Reactor)

Previously, experiments were conducted to determine the effects of parameters and dispersion on heat transfer during air-assisted spray cooling. Variables examine were the parameters affecting flow and heat transfer processes, arrangement of fins, air and liquid flow rates, fin heights, and spray duration in hexagonal heat sinks to determine the specified optimum geometric and flow parameters for hexagonal finned heat sinks. Experiments were conducted at a constant surface temperature. A Taguchi $L_{18}\left(2^{1 *} 3^{7}\right)$ standard orthogonal array was chosen as the experimental layout. Based on the results of the Taguchi experiments, we performed the experiments under optimum conditions. Experiments were conducted under optimized conditions using manufactured optimum heat sinks. (Fig. 2). 

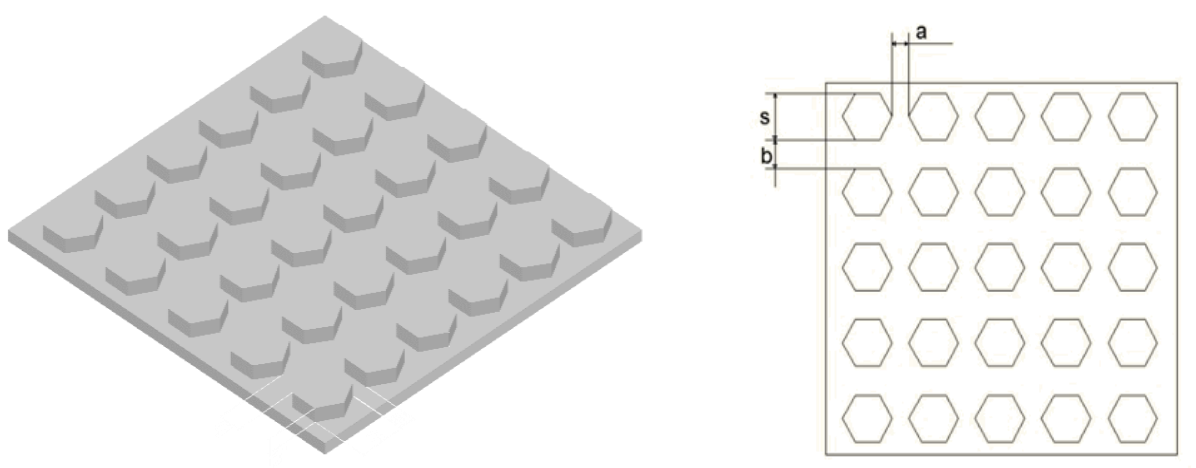

Figure 2. Optimal geometry of the hexagonal finned heat sink

Optimum geometric parameters investigated in this study are shown in Figure 2. All optimized parameters are classified in Table 1.

Table 1. Optimized Parameters

\begin{tabular}{c|c}
\hline \hline Symbol & Main parameters \\
\hline \hline$H / d$ & $\mathrm{H} / \mathrm{d}$ rate \\
$h_{k}$ & Fin height [mm] \\
$s$ & Fin width [mm] \\
$a$ & Distance to $\mathrm{x}$ direction between fins $[\mathrm{mm}]$ \\
$b$ & Distance to y direction between fins $[\mathrm{mm}]$ \\
$Q_{a}$ & Air flow rate $\left[\mathrm{m}^{3} / \mathrm{h}\right]$ \\
$Q_{l}$ & Liquid flow rate $\left[\mathrm{m}^{3} / \mathrm{h}\right]$ \\
$t$ & Spraying time $[\mathrm{s}]$
\end{tabular}

\section{Results and discussion}

Examined parameters and their values are given in Table 2. Eight parameters were examined: one at two levels $(\mathrm{H} / \mathrm{d})$ and seven at three levels. The optimized results were found to be a nozzle-surface distance of $400 \mathrm{~mm}$, fin height of $10 \mathrm{~mm}$, fin width of $36 \mathrm{~mm}$, distance to $x$ direction between fins of $15 \mathrm{~mm}$, distance to y direction between fins of $10 \mathrm{~mm}$, air-flow rate of $3.6 \mathrm{~m}^{3} / \mathrm{h}$, water flow rate of $0.03 \mathrm{~m}^{3} / \mathrm{h}$ and spraying time of 5 seconds. Later, detailed graphs were drawn according to experiments with these optimum values. In this study, the variations of the two most influential parameters are presented related to Nusselt number and ALR (Figure 5-6).

Table 2. Investigated flow parameters and their levels

\begin{tabular}{c|ccc}
\hline \hline Factor & Level 1 & Level 2 & Level 3 \\
\hline \hline$H / d$ & $800 / 1.2$ & $400 / 1.2$ & --- \\
$h_{k}$ & 10 & 15 & 20 \\
$s$ & 14 & 26 & 36 \\
$a$ & 10 & 15 & 20 \\
$b$ & 10 & 15 & 20 \\
$Q_{a}$ & 2.1 & 2.9 & 3.6 \\
$Q_{l}$ & 0.012 & 0.021 & 0.03 \\
$t$ & 5 & 10 & 15
\end{tabular}

Using the estimation method proposed by Kline and McClintock [20], the maximum uncertainties of the investigated parameters were calculated (Table 3). Uncertainty analysis was carried out with respect to the Nusselt number, Weber number, Reynolds number, and ALR. 
Table 3. Uncertainties in the values of variables

\begin{tabular}{l|c}
\hline \hline \multicolumn{1}{c|}{ Variable } & Relative Uncertainty $\left(\mathbf{W}_{\mathbf{R}}\right)$ \\
\hline \hline Mass of aluminium, $m$ & 0.09 \\
Surface temperature, $T_{s}$ & 0.09 \\
Fluid temperature, $T_{s p}$ & 0.09 \\
Water flow-rate, $Q_{l}$ & 0.03 \\
Air flow-rate, $Q_{a}$ & 0.05 \\
Nozzle diameter, $d_{0}$ & 0.025 \\
Surface tension, $\sigma$ & 0.001
\end{tabular}

The changes of ALR-SMD for water and air-flow rates presented in Figure 3 were drawn with the correlations of Feras and Shanawany. The value of SMD decreased as ALR increased.

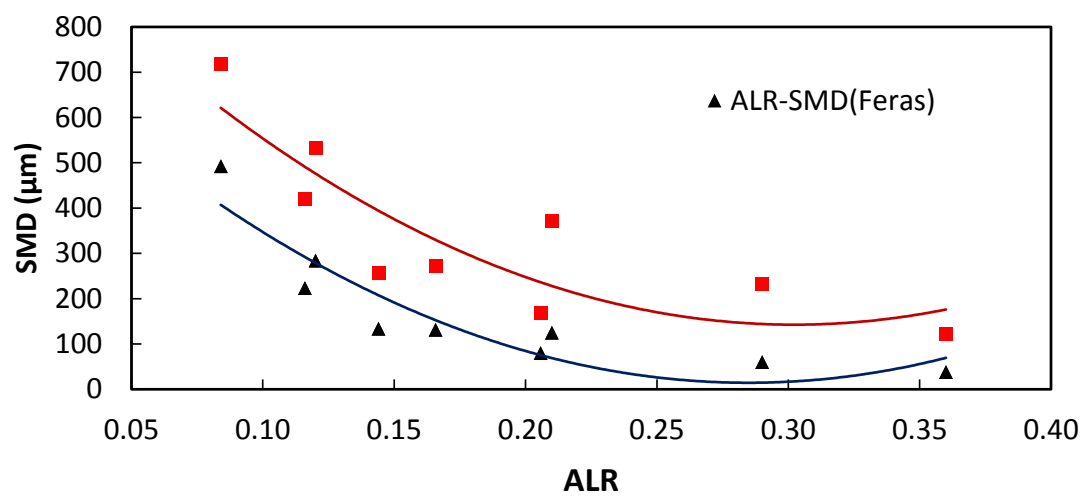

Figure 3. The relationship of ALR-SMD with the correlations of Feras and Shanawany.

In Figure 3, SMD is seen to decrease as ALR increases in accordance with the literature. These correlations were chosen to show the decline. There are many SMD correlations in the literature for various operational and geometric conditions [19], [21].

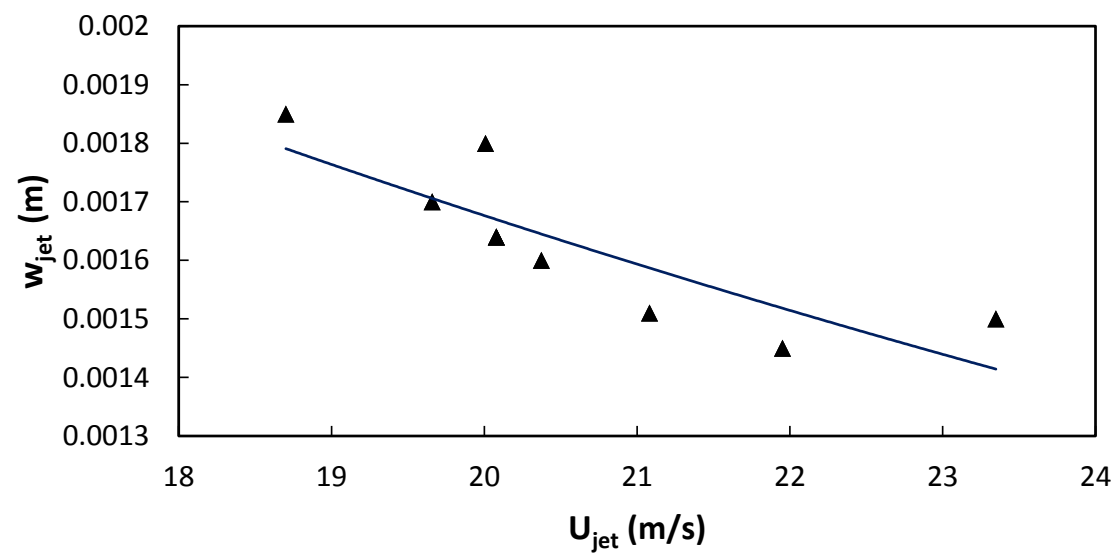

Figure 4. The relationship of jet width to jet velocity

It can be seen in Figure 4 that jet velocity decreased as jet width increased. The parameters that affect Nusselt number are spraying time $(t)$, fin height $\left(h_{k}\right)$, air-flow rate $\left(Q_{a}\right)$, fin width $(s)$, water flow rate $\left(Q_{l}\right)$, the distance between fins in the directions of $y(b)$ and $x(a)$, and the distance between nozzle and surface $(H / d)$. The parameters with the greatest impact on the Nusselt number is spraying time. When the spraying time was $5 \mathrm{~s}$, the Nusselt number reached the maximum value. No investigation has been done for spraying times below this value. According to the experiments designed using the Taguchi method, the changes in ALR-Nu are based on spraying time $(t)$ and fin height $\left(h_{k}\right)$. 


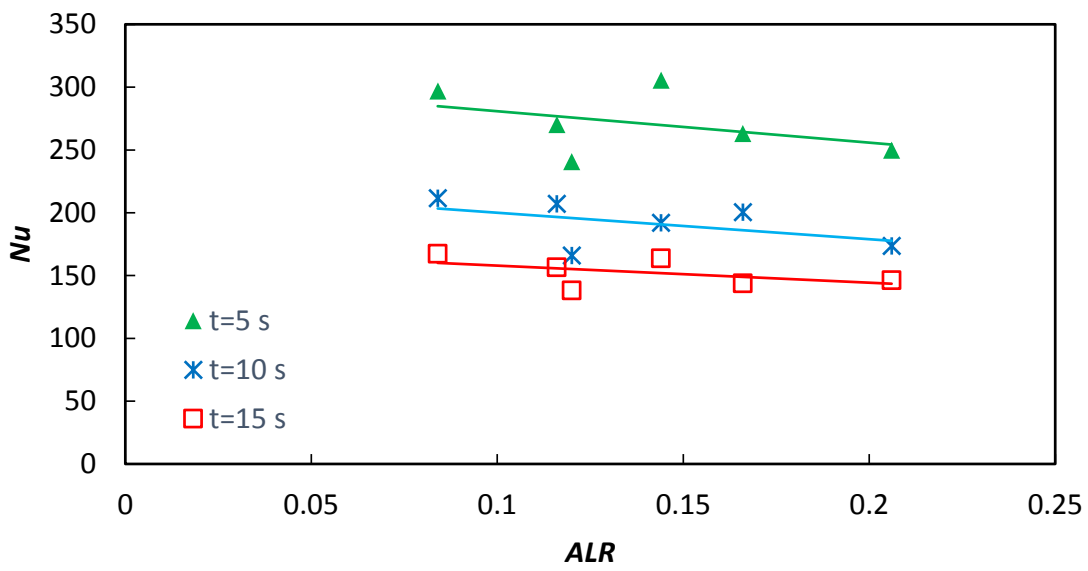

Figure 5. Nusselt vs. ALR as a function of spraying time

The changes in ALR-Nu related to spraying time are presented in Figure 5. The maximum Nusselt number was obtained for $5 \mathrm{~s}$ spraying time. Nusselt number decreased as the spraying time decreased.

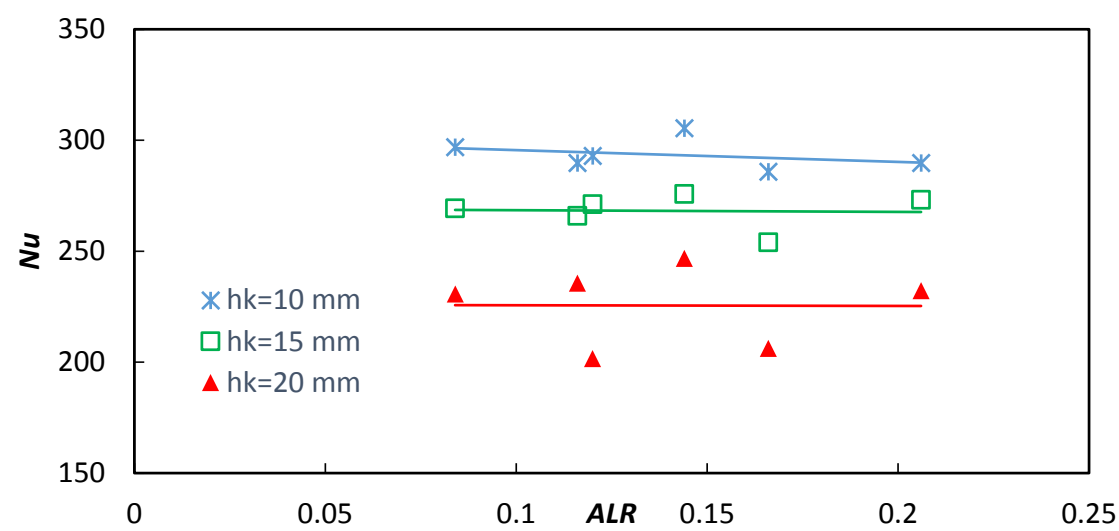

Figure 6. Nusselt vs. ALR as a function of fin height

The change in ALR-Nu correlate to fin height in Figure 6. The maximum Nu value was obtained when the fin height was $10 \mathrm{~mm}$. A significant increase was observed in Nu number with the decrease of $h_{k}$. There is an inverse relationship fin height and Nu number: As the fin height increases, the Nusselt number decreases. The Nusselt number does not change significantly as ALR increases. The jet diameter and spray angle were determined via image processing with Matlab GUI using macroscopic aspects (Fig. 7). There are various ways to define the spray cone angle [22], but in this study it is defined as the angle between the maximum left and right positions at a halflength of the spray tip penetration from the nozzle tip [23].

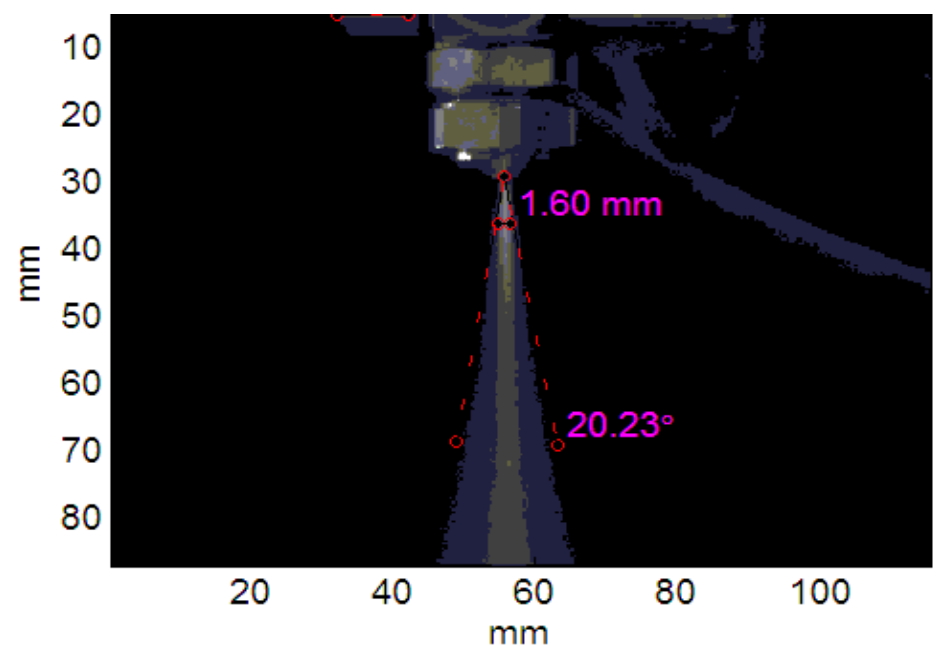

Figure 7. Image-processing analysis with MATLAB GUI for spray angle and jet width 
Nu number, spray-angle and jet-diameter correlations were obtained as follows in the experiments performed on the optimized heat sink geometry. These correlations were obtained as a result of 54 experiments. Experimental findings obtained at various ALR ratios in the DXD-HS1 air-assisted nozzle and correlations with the "Custom Loss" function in the STATISTICA program for Nu number, spray angle and jet width were obtained. Correlations were obtained according to a least square procedure.

$$
\begin{array}{ll}
N u=0.7797 A L R^{-0.1} t^{-0.58} h_{k}^{-0.18} s^{34.37} a^{76.13} b^{-38.43}\left(\frac{H}{d}\right)^{-40.25} & (\mathrm{R}=0.90) \\
\theta=1.16347 * A L R^{-0.18} W e^{-0.05}\left(P_{a} / P_{l}\right)^{0.17} \mathrm{Pr}^{1.56} & (\mathrm{R}=0.98) \\
w_{j e t}=0.06782 * A L R^{0.65} W e^{0.1}\left({ }^{P} / P_{l}\right)^{-0.14} \mathrm{Pr}^{-1.65} & (\mathrm{R}=0.84)
\end{array}
$$

\section{Conclusions}

An experimental study was carried out to determine heat transfer and flow characteristics of spray cooling for aluminum hexagonal finned heat sinks. The optimized geometric and flow parameters of water spray cooling were analyzed under a non-boiling regime. Experiments were conducted for optimum conditions, and based on these, the following observations were drawn. The changes in Nu-ALR for different spraying time, fin heights, and fin width parameters significantly affected the Nusselt number. The maximum Nusselt number was obtained for a $5 \mathrm{~s}$ spraying time. It was observed that the Nusselt number increased as the spraying time decreased. But did not increase significantly with $A L R$ for all fin heights. There is an inverse relationship between fin height and Nu number. Convective heat transfer increased with the liquid flow rate in all ALR values, while heat flux increased with water flow because of the increase in heat transfer related to increasing droplet intensity. Nu number, spray angle and jet width correlations were obtained in the experiments performed on the optimized heat sinks.

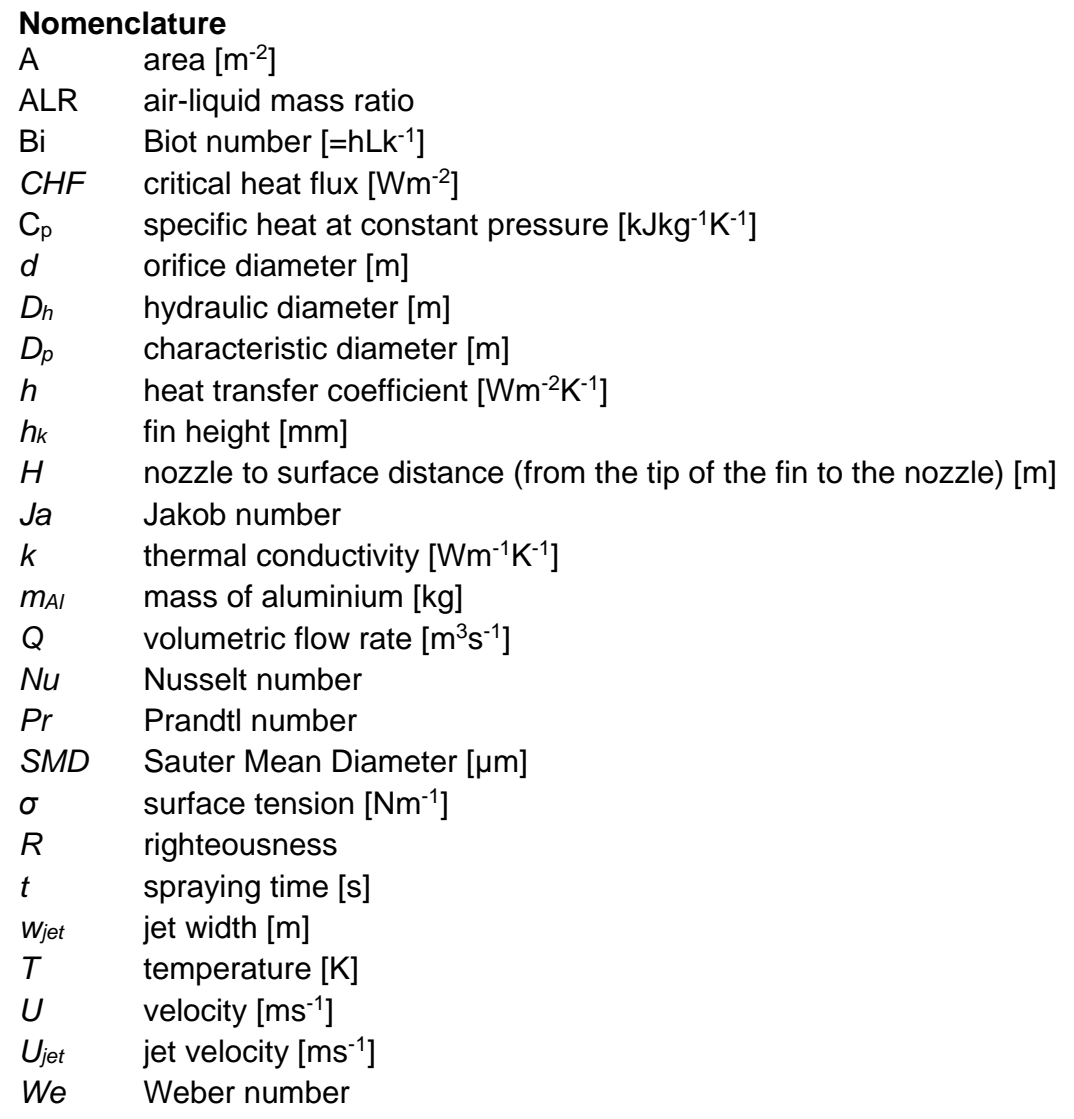




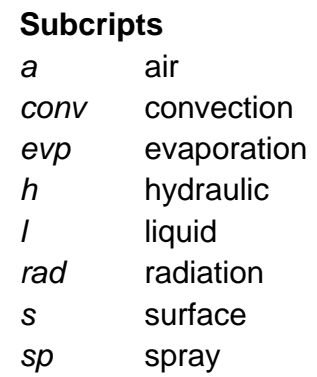

\section{References}

[1] Wang, X., Lu, G., Peng, X., and Wang, B., "Evaporation and nucleate boiling of an individual droplet on surfaces," Proc. ASME 2005 Summer Heat Transfer Conference collocated with the ASME 2005 Pacific Rim Technical Conference and Exhibition on Integration and Packaging of MEMS, NEMS, and Electronic Systems, American Society of Mechanical Engineers, pp. 703-710.

[2] Rybicki, J. R., and Mudawar, I., 2006, "Single-phase and two-phase cooling characteristics of upward-facing and downward-facing sprays," International Journal of Heat and Mass Transfer, 49(1), pp. 5-16.

[3] Somasundaram, S., and Tay, A., 2013, "Comparative study of intermittent spray cooling in single and two phase regimes," International Journal of Thermal Sciences, 74, pp. 174-182.

[4] Liu, M., Wang, Y., Liu, D., Xu, K., and Chen, Y., 2011, "Experimental study of the effects of structured surface geometry on water spray cooling performance in non-boiling regime," Frontiers in Energy, 5(1), pp. 75-82.

[5] Sridhara, S., and Raghunandan, B., 2010, "Photographic investigations of jet disintegration in airblast sprays," Journal of applied fluid mechanics, 3(2), pp. 111-123.

[6] Charalampous, G., Hadjiyiannis, C., Hardalupas, Y., and Taylor, A., "Measurement of continuous liquid jet length in atomizers with optical connectivity, electrical conductivity and high-speed photography techniques," Proc. 23rd Annual Conference on Liquid Atomization and Spray Systems, ILASS-Europe.

[7] Karwa, N., Kale, S. R., and Subbarao, P., 2007, "Experimental study of non-boiling heat transfer from a horizontal surface by water sprays," Experimental Thermal and Fluid Science, 32(2), pp. 571-579.

[8] Tao, Y., Huai, X., Wang, L., and Guo, Z., 2011, "Experimental characterization of heat transfer in non-boiling spray cooling with two nozzles," Applied Thermal Engineering, 31(10), pp. 1790-1797.

[9] Sharief, R. A., Jeong, J. R., and James, D. D., 2000, "The performance characteristics of solid-cone-spray pressure-swirl atomizers," 10(6), p. 20.

[10] Nikolopoulos, N., Strotos, G., Nikas, K.-S. P., Gavaises, M., Theodorakakos, A. P., Marengo, M., and Cossali, G. E., 2010, "Experimental investigation of a single droplet impact onto a sessile drop," 20(10), pp. 909-922.

[11] Batarseh, F. Z., Roisman, I. V., and Tropea, C., 2010, "Characterization of a spray generated by an airblast atomizerwith prefilmer," 20(10), pp. 887-903.

[12] Desantes, J. M., Payri, R., Pastor, J. M., and Gimeno, J., 2005, "Experimental characterization of internal nozzle flow and diesel spray behavior. part i: nonevaporative conditions," 15(5), pp. 489-516.

[13] Marengo, M., Antonini, C., Roisman, I. V., and Tropea, C., 2011, "Drop collisions with simple and complex surfaces," Current Opinion in Colloid \& Interface Science, 16(4), pp. 292-302.

[14] Issa, R. J., 2009, Multiphase spray cooling technology in industry, INTECH Open Access Publisher.

[15] Davies, T., 2011, "Biot number."

[16] Çengel, Y. A., and Ghajar, A. J., 2015, Heat and mass transfer : Fundamentals \& Applications.

[17] Batarseh, F. Z. M., 2009, "Spray generated by an airblast atomizer: atomization, propagation and aerodynamic instability," Technische Universität.

[18] El-Shanawany, M., and Lefebvre, A., 1980, "Airblast atomization: effect of linear scale on mean drop size," Journal of Energy, 4(4), pp. 184-189.

[19] Lefebvre, A., 1988, Atomization and sprays, CRC press.

[20] Kline, S., and McClintock, F., 1953, "Analysis of uncertainty in single-sample experiments," Mechanical Engineering, 75.

[21] Ashgriz, N., 2011, Handbook of atomization and sprays: theory and applications, Springer Science \& Business Media.

[22] Payri, R., Salvador, F., Gimeno, J., and De la Morena, J., 2008, "Macroscopic behavior of diesel sprays in the near-nozzle field," SAE International Journal of Engines, 1(2008-01-0929), pp. 528-536.

[23] Kim, H. J., Park, S. H., and Lee, C. S., 2010, "A study on the macroscopic spray behavior and atomization characteristics of biodiesel and dimethyl ether sprays under increased ambient pressure," Fuel processing technology, 91(3), pp. 354-363. 